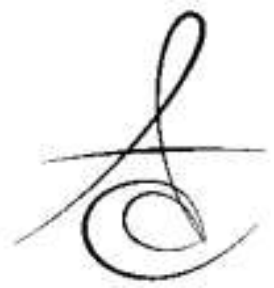

\title{
TEMPOROMANDİBULAR EKLEM AĞRISININ MİGREN, OTOLOJİK SEMPTOMLAR, BAŞ DÖNMESİ VE BOYUN/OMUZ AĞRISI İLE İLIŞKİSİNİN RETROSPEKTİF OLARAK DEĞERLENDİRİLMESİ
}

\author{
RETROSPECTIVE EVALUATION OF THE RELATIONSHIP BETWEEN \\ TEMPOROMANDIBULAR JOINT PAIN WITH MIGRAINE, OTOLOGICAL \\ SYMPTOMS, DIZZINESS AND NECK/SHOULDER PAIN
}

\author{
Dr. Öğr. Üyesi Zeynep GÜMRÜKçÜ* \\ Arş. Gör. Mert KARABAĞ ${ }^{*}$
}

\author{
Dr. Öğr. Üyesi Emre BALABAN* \\ Dr. Öğr. Üyesi Emine DEMİR*
}

\author{
Makale Kodu/Article code: 4111 \\ Makale Gönderilme tarihi: 24.06 .2019 \\ Kabul Tarihi: 11.10 .2019
}

DOI : $10.17567 /$ ataunidfd.632067
Zeynep Gümrükçü: ORCID NO: 0000-0002-5910-2218

Emre Balaban: ORCID NO: 0000-0001-5399-2152

Mert Karabağ: ORCID NO: 0000-0003-1387-4367

Emine Demir: ORCID NO: 0000-0003-4087-432X

\section{öz}

Amaç: Bu çalışmanın amacı temporomandibuler eklem (TME) ağrısı vizüel analog skala (VAS) değerleri ile migren, kulak çınlaması, duyma kaybı, baş dönmesi, boyun/omuz ağıısı arasındaki ilişkiyi değerlendirmektir.

Materyal ve metod: Çalışmaya, Temmuz 2018 ve Mayıs 2019 tarihleri arasında TME ağrısı şikayeti ile Recep Tayyip Erdoğan Üniversitesi, Diş Hekimliği Fakültesi, Ağız Diş Çene ve Cerrahisi Anabilim Dalı'na başvuran 61 hasta dahil edilmiştir. Kayıtlar arasından TME-VAS skorları (0-10) ile kulak çınlaması, baş dönmesi, migren, boyun ve omuz ağrısı ve işitme kaybı (var/yok) arasındaki ilişki değerlendirildi.

Bulgular: Çalışmaya yaşları 14 ile 87 arası sırada değişen 61 hasta (ortalama: $33.0 \pm 15.5$ ) dahil edildi. Migren hastalarında anlamlı derecede yüksek TME-VAS skorları bulundu $(P=0.017)$. Boyun ağrısı olan hastalarda VAS skoru istatistiksel olarak anlamlı düzeyde yüksek bulundu ( $\mathrm{p}=0,036)$. Tinnitus, baş dönmesi, omuz ağrısı, işitme kaybı ve TME-VAS skoru arasında anlamlı fark bulunmadı ( $p>0.05$ ).

Sonuç: TME ağrısı komşu ve benzer sinir iletim yollarına sahip olduğundan migrenle ilişkilidir bu sebeple migren tanılı hastalarda VAS skoru daha yüksek olabilir. Boyun ağrıSı olan hastalarda TME-VAS skoru daha yüksektir.

Anahtar Kelimeler: Temporomandibular eklem, ağrı, kulak çınlaması, migren, omuz ağrısı, boyun ağrısı

\section{ABSTRACT}

Aim: The aim of this study was to evaluate the relationship between temporomandibular joint (TMJ) pain visual analog scale scores (VAS) with migraine, tinnitus, hear loss, dizziness and shoulder/neck pain in patients with temporomandibular joint pain. Materials and Methods: The study included 61 patient's records who were presented to the Department of Oral and Maxillofacial Surgery, Faculty of Dentistry, Recep Tayyip Erdoğan University between July 2018 and May 2019 with the complaint of TMJ pain. The relationship between visual analog scale (VAS) scores (0-10) with tinnitus, dizziness, migraine, neck/shoulder pain and hear loss (absent/present) were evaluated.

Results: Sixty one patient, aged from 14 to 87 (Mean: 33.0 15.5 ), were evaluated in this study. Significantly higher TMJ-VAS scores were found in patients with migraine relative to without migraine $(P=0.017)$. Significantly higher TMJ-VAS scores were found in patients with neck pain $(p=0.036)$. Any statistically significant difference was not found between tinnitus, dizziness, shoulder pain, hear loss and VAS score $(p>0.05)$.

Conclusion: TMJ pain is associated with migraine because it has adjacent and similar nerve conduction pathways, so the VAS score may be higher in patients diagnosed with migraine. TMJ-VAS score is higher in patients with neck pain.

Keywords: Temporomandibular joint, pain, tinnitus, migraine, shoulder pain, neck pain

*Ağız Diş ve Çene Cerrahisi Anabilim Dalı, Diş Hekimliği Fakültesi, Recep Tayyip Erdoğan Üniversitesi, Rize, Türkiye ${ }^{* *}$ Kulak Burun Boğaz Anabilim Dalı, Tıp Fakültesi, Recep Tayyip Erdoğan Eğitim ve Araștırma Hastanesi, Rize, Türkiye

Kaynakça Bilgisi: Gümrükçü Z, Balaban E, Karabağ M, Demir E. Temporomandibular Eklem Ağrısının Migren, Otolojik Semptomlar, Baş Dönmesi ve Boyun/Omuz Ağrısı ile İliş̧kisinin Retrospektif Olarak Değerlendirilmesi. Atatürk Üniv Diş Hek Fak Derg 2020; 30: 83-87.

Citation Information: Gumrukcu Z, Balaban E, Karabag M, Demir E. Retrospective Evaluation of the Relationship Between Temporomandibular Joint Pain with Migraine, Otological Symptoms, Dizziness and Neck/Shoulder Pain. J Dent Fac Atatürk Uni 2020; 30: 83-87 


\section{GİRİŞ}

Temporomandibular eklem (TME) fibröz kapsül, eklem diski sinoviyal sıvı, sinoviyal membran ve ligamentlerden oluşan, fonksiyon esnasında kayma ve rotasyon hareketleri yapabilen bikondiler bir eklemdir. ${ }^{1,2}$ Temporomandibular eklem disfonksiyonu(TMED) ilgili bölgedeki kasların, ligamentlerin yada temporomandibular eklemin kendisini içeren bulguların bozukluğunu anlatan genel bir terimdir. ${ }^{3}$ TMED'nin etiyolojisinde; kraniofasiyal tramva, diş eksikliği, stres ve psikolojik sorunlar, anatomik malformasyonlar, bruksizm, uzun süren dental tedaviler, oral alışkanlıklar, çiğneme kaslarında spazm gibi faktörler yer almaktadır. ${ }^{4}$ TMED ile ilgili genel bulgular; normal sınırların dışında eklem hareketleri, çiğneme kaslarında ağrı, temporomandibular eklem bölgesinde ses ve preauriküler ağrıdır., 5

TMED'nin semptomları genel olarak belirlenmiş olmakla birlikte, TMED'de tanıya yardımcı olabilecek birçok kriter bulunduğu bilinmektedir. ${ }^{7}$ Çiğneme kaslarında ağrı, temporomandibular eklemde ses ve diğer genel bulguların yanı sıra TMED'de kulak ve başboyun bulguları da sıkça görülmektedir. ${ }^{8,9}$ Tinnitus (kulak çınlaması) ve kulak ağrısı (otalji) temporomandibular eklem disfonksiyonunda görülen kulak bulguları arasında yer almaktadır. ${ }^{10-12}$

TME, anatomisi itibariyle baş boyun bölgesindeki diğer anatomik yapılarla yakın ilişki içerisindedir ve TMED'de baş-boyun bölgesini ilgilendiren bulgular sıkça görülmektedir. ${ }^{1,9}$ Baş bölgesiyle ilgili sık görülen bulgular arasında baş ağrısı ve baş dönmesi yer almaktadır. ${ }^{13-16}$ Miyofasiyal kökenli ağrı ya da eklem patolojisine bağı olarak görülen baş ağrısı kronik bir bulgu olarak TMED hastalığında yer almıştır. ${ }^{14}$ Daha az nadir olmakla birlikte baş-boyun bölgesinde, TMED ile birlikte görülen bir diğer durum da migrendir. ${ }^{17,18}$

$\mathrm{Bu}$ çalışmanın amacı kliniğimize temporomandibular eklem disfonksiyonu şikayetleriyle başvuran hastalarda eklem ağrısı ile migren, tinnitus, baş dönmesi/ağrısı, duyma kaybı, omuz/boyun ağrısı bulguları arasındaki ilişkinin değerlendirilmesidir.

\section{MATERYAL VE METOD}

Çalışma Recep Tayyip Erdoğan Üniversitesi, Diş Hekimliği Fakültesi, Ağız Diş ve Çene Cerahisi Kliniği'ne Temmuz 2018-Mayıs 2019 tarihleri arasında TME şikayetiyle başvuran 61 hastanın kaydedilmiş verileri üzerinden yürütülmüştür. Önceden bilinen bir nörolojik problemi olan, iskelet-kas sistemi hastalığı bulunan veya TMED ile ilgili herhangi bir cerrahi tedavi veya medikal tedavi görmüş hasta kayıtları çalışmaya dahil edilmemiştir. Çalışmaya dahil edilen hastaların 47'si kadın 14'ü erkektir.

Çalışma protokolü, tüm değişiklikleri ve revizyonları içeren Helsinki Deklarasyonu'nda açıklanan prensiplere göre gerçekleştirilmiştir. Kliniğe eklem şikayeti ile gelen hastaların tümü uygulanacak tedavi hakkında bilgilendirilmiş ve muayene öncesi yazılı ve sözlü onamları alınmıştır. Rutin olarak kaydedilen verilerin çalışma amaçlı kullanımı için Recep Tayyip Erdoğan Üniversitesi, Girişimsel Olmayan Klinik Araştırmalar Etik Kurulun'na başvuru yapılmış ve çalışma 20.06.2019 tarihli ve 99 sayılı kararı ile onaylanmıştır.

Çalışmaya dahil edilen hastalara ait bilgiler, kliniğe başvurmuş olan hastaların rutin olarak tutulan TME muayene kayıt formaları üzerinden elde edilmiştir. Formlarda kaydedilmiş olan veriler arasından; yaş, cinsiyet, tıbbi anamnez, eklem bölgesinde ağrı, duyma kaybı, kulak çınlaması (tinnitus), baş dönmesi, omuz ağrısı, migren, boyun ağrısı verileri seçilmiştir.

TME ağrı düzeyini belirlemek için Vizüel Analog Skala (VAS) skorları kullanılmıştır (0-10 arasında kalibre edilmiş skor değerleri seçilerek). Migren, baş dönmesi, tinnitus, duyma kaybı ve omuz/boyun ağrısı parametreleri ise var ya da yok şeklinde kayıt altına alınan veriler üzerinden yürütülmüştür.

Tüm veriler istatistiksel analiz programına Statistical Package for Social Science (SPSS) 20.0 (SPSS Inc., Chicago, IL, ABD) aktarılarak değerlendirmeye hazır hale getirilmiştir. Frekans Analizi ve Ki-kare analizi ile veriler analize tabi tutulmuştur. İstatistiksel anlamlılık $\mathrm{p}<0.05$ olarak kabul edilmiştir.

\section{BULGULAR}

Çalışma, yaş aralığı 14-87 olan ve ortalama yaşı

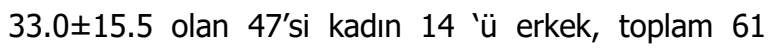
hasta verisi üzerinden yürütülmüştür. Çalışmada duyma problemi olan 6, olmayan 55 hasta bulunmaktadır. İstatistiksel analiz sonucuna göre duyma problemi ve TME-VAS değerleri arasında istatistiksel olarak anlamlı bir ilişki bulunamamıştır $(P=0.121)$ (Tablo 1).

Çalışmada tinnitus tespit edilen 17 , edilmeyen 44 hasta bulunmaktadır. Çalışma analizi sonucunda tinnitus ile VAS değerleri arasında istatistiksel olarak anlamlı bir ilişki bulunmamıştır $(P=0.095)$ (Tablo 2). 
Tablo 1. Duyma kaybı ve TME-VAS arasındaki ilişkinin değerlendirilmesi

\begin{tabular}{cccc}
\hline $\begin{array}{c}\text { Duyma } \\
\text { Kaybı }\end{array}$ & N & VAS Skoru (0-10) & $\boldsymbol{p}$ \\
\cline { 1 - 3 } Var & 6 & $6.0 \pm 4.0(0-10)$ & 0.121 \\
\hline Yok & 55 & $5.3 \pm 2.7(0-10)$ & \\
\hline N: Hasta sayıS VAS: Vizüel Analog Skala &
\end{tabular}

Tablo 2. Tinnitus ile TME-VAS arasındaki ilişkinin değerlendirilmesi

\begin{tabular}{cccc}
\hline Tinnitus & N & VAS Skoru (0-10) & $\boldsymbol{p}$ \\
\cline { 1 - 3 } Var & 17 & $6.5 \pm 2.5(2-10)$ & \\
\cline { 1 - 2 } Yok & 44 & $4.9 \pm 2.9(0-10)$ & 0.095 \\
\hline \multicolumn{2}{l}{ N: Hasta sayISI VAS: Vizüel Analog Skala } &
\end{tabular}

Çalışma verileri arasında, baş dönmesi olan 9 olmayan 52 hasta verileri istatistiksel olarak incelendiğinde, baş dönmesi ile TME ağrısı VAS değeri arasında istatistiksel olarak anlamlı bir ilişki bulunamamiştır ( $\mathrm{P}=0.533)$ (Tablo 3).

Tablo 3. Baş dönmesi ile TME-VAS arasındaki ilişkinin değerlendirilmesi

\begin{tabular}{cccc}
\hline Baş Dönmesi & N & VAS Skoru (0-10) & $\boldsymbol{p}$ \\
\cline { 1 - 3 } Var & 9 & $6.5 \pm 1.9(4-10)$ & \\
\cline { 1 - 3 } Yok & 52 & $5.1 \pm 2.9(0-10)$ & 0.533 \\
\hline
\end{tabular}

N: Hasta sayISI VAS: Vizüel Analog Skala

Çalışma verileri arasında, omuz ağrısı olan 20, olmayan 41 hasta verileri üzerinden yapılan analiz sonucunda, omuz ağrısı ile TME-VAS değerleri arasında istatistiksel olarak anlamlı bir ilişki bulunamamıştır $(P=0.305)$ (Tablo 4).

Tablo 4. Omuz ağrısı ile TME-VAS değeri arasındaki ilişkinin değerlendirilmesi

\begin{tabular}{cllc}
\hline Omuz ağrısı & N & VAS Skoru (0-10) & $\boldsymbol{p}$ \\
\hline Var & 20 & $6.5 \pm 2.3(2-10)$ & \\
\cline { 1 - 3 } Yok & 41 & $4.8 \pm 2.9(0-10)$ & 0.305 \\
\hline
\end{tabular}

N: Hasta sayISI VAS: Vizüel Analog Skala

Çalışmadaki tanılı migreni olan 4, olmayan 57 hasta verisinin analizi sonucunda, baş ağrısı ile TME ağrısı VAS değerleri arasında istatistiksel olarak anlamlı bir ilişki bulunmuştur ve migreni olan hastalarda TMEVAS skorlarının daha yüksek olduğu belirlenmiştir $(P=0.017)$ (Tablo 5).

Çalışmadaki boyun ağrısı olan 22 ve olmayan 39 hasta verileri analiz edildiğinde, boyun ağrısı ile TME-VAS değerleri arasında istatistiksel olarak anlamlı bir ilişki bulunmuştur, boyun ağrısı olan hastalarda TME-VAS skorlarının daha yüksek olduğu görülmüştür $(P=0.036)$ (Tablo 6).

Tablo 5. Migren ile TME-VAS değeri arasındaki ilişkinin değerlendirilmesi

\begin{tabular}{clll}
\hline Migren & N & VAS Skoru (0-10) & $\boldsymbol{p}$ \\
\hline Var & 4 & $6.5 \pm 4.1(2-10)$ & \\
\cline { 1 - 3 } Yok & 57 & $5.3 \pm 2.8(0-10)$ & 0.017 \\
\hline N: Hasta sayıSI VAS: Vizüel Analog & Skala &
\end{tabular}

N: Hasta sayısı VAS: Vizüel Analog Skala

Tablo 6. Boyun ağrısı ile TME-VAS değeri arasındaki ilişkinin değerlendirilmesi

\begin{tabular}{clll}
\hline Boyun Ağrısı & N & $\begin{array}{l}\text { VAS Skoru (0- } \\
\text { 10) }\end{array}$ & $\boldsymbol{p}$ \\
\cline { 1 - 3 } & 22 & $6.2 \pm 2.4(2-10)$ & \\
\cline { 1 - 3 } Var & 39 & $4.9 \pm 3.0(0-9)$ & 0.036 \\
\hline
\end{tabular}

N: Hasta sayısı VAS: Vizüel Analog Skala

\section{TARTIŞMA}

Parafonksiyonel alışkanlıkların stomatognatik sistemi direkt olarak etkilediği, özellikle kaslar ve TMED üzerinde etkili olduğu bilinmektedir. Parafonksiyonel alışkanlık olarak TMED'nin etiyolojisinde yer alan faktörlerden diş hekimliğinde en çok karşımıza çıkanı bruksizmdir. Bu faktör, özellikle kaslarda gerilim, hassasiyet ve ağrıya neden olabilecek birincil etkenler arasında sayılabilmektedir. Bahsi geçen ağrı, baş boyun bölgesinin çeşitli kısımlarında lokalize olabilmektedir ve çoğunlukla da TME ağrısı ile karıştığı bilinmektedir. ${ }^{19}$ Ağrı yaratan durum, TME tarafında kompanse edilip fonksiyon anlamında kısa vadede bir sorun ile karşılaşılmasa bile zamanla bu durum TMED gelişimini tetiklemektedir. $^{20}$

Literatürde, TME hastalarında en sık belirtilen semptomlar; kulakta çınlama, otalji, kulakta doluluk hissi, işitme kaybı ve baş dönmesidir. Literatürde TME ağrısı etiyolojisinin multifaktöriyel olduğu belirtilmesine rağmen ve bahsedilen bu semptomlar ile TME ağrısının ilişkisi henüz netleştirilememiştir. ${ }^{3,11}$ Literatürde otalji, migren ile TME ağrısı arasında ilişkinin değerlendirildiği birçok çalışma olsa da ${ }^{8,11,15,16,19,20}$, tüm bu parametrelerin aynı çalışmada değerlendirildiği bir çalışmaya rastlanılmamıştır. Bu anlamda mevcut çalışma, rapor edilen diğer çalışmaların parametrelerini de kapsayan daha geniş kapsamlı kıymetli bir çalışmadır.

Çalışma sonuçlarımıza göre, migren ile TME ağrıSı arasında ilişki olduğu, migren tanısı alan hastalarda TME ağrısı VAS değerlerinin anlamlı düzeyde yüksek bulunduğu bilgisi literatüre sunulmuştur. 
Fernandes ve arkadaşları ${ }^{18}$, yapmış oldukları çalışmada sonucunda migren ve baş ağrısının TMED ile güçlü bir şekilde ilişkili olduğunu, fakat tansiyon tipli baş ağrısı ile TME ağrısı arasında ilişki olmadığını rapor etmişlerdir. Yapılan birçok çalışma, TME ağısı ile migren arasındaki ilişkiyi destekler niteliktedir ve bu raporlar çalışma verilerimizle uyumludur.

Ağrı gelişiminin patofizyolojisine bakılacak olursa, migren ve TME ağrısının patofizyolojisinin benzer olduğu rapor edilmiştir. Trigeminal sinirin 1 . dalının migrenden, 2 . ve 3 . dalının ise TME ağrısında sorumlu olduğu bilinmektedir. Trigeminal sinirin 3 . dalındaki uyarının, 1 . ve 2 . dalındaki sinirleri de etkileyebileceği ve bu sebeple de TME ağrısı olan bireylerde migren prevalansının yüksek olabileceği bilgisi literatüre sunulmuştur. ${ }^{21}$ Kaslardan veya TME'den gelen nosiseptif uyarıların trigeminal sinir kaudalini etkileyip migren atağını tetikleyebileceği gibi, bunun tersinin de mümkün olduğu belirtilmiştir. ${ }^{22} \mathrm{Bu}$ bilgiler, çalışma sonucumuzu destekler niteliktedir.

Felicio ve arkadaşları ${ }^{23}$, bruksizmin kas hassasiyetine ve TME ağrısına neden olduğunu belirtmişlerdir. Bununla birlikte çiğneme kaslarındaki hiperaktivitenin tensör timpani kasında da anormal aktivite oluşturacağını, auditör kanalda değişiklik oluşturacağı ve bunun sonucunda orta kulağın ventilasyonunu bozabileceği ve bu gerekçeyle tinnitusu tetikleyebileceği ve baş dönmesi üzerinde etkili olabileceği bilinmektedir. ${ }^{20,23}$ Mevcut çalışmada, baş dönmesi, kulak çınlaması, duyma kaybı ile TME ağrısı VAS değeri arasında anlamlı ilişki bulunmamışıı. Bu sonuç, tinnitus ve baş dönmesi bakımından Felicio ve arkadaşlarının çalışma sonuçları ile çelişmektedir. Çalışmalar arasındaki bu sonuç farklııılarının çalışma dizaynı, hasta sayısı, demografik veriler arasındaki farklııklardan kaynaklanabileceği düşünülmektedir.

Mevcut çalışmada, boyun ağrısı olan hastalarda TME-VAS ağrı değerleri anlamlı düzeyde yüksek bulunmuştur. Maciel ve arkadaşları yapmış oldukları çalışmada 251 hasta verisini değerlendirmişler ve çalışma sonucu olarak da TMED ile boyun ağrısı arasında istatistiksel olarak anlamlı bir ilişki rapor etmişlerdir. Yapılan başka bir çalışmada, boyun kaslarındaki trigger nokta sayısının, TMED hastalarında, sağlıklı TME'ye sahip hastalardan daha yüksek oranda görüldüğünü rapor edilmiştir. ${ }^{24}$ Mevcut çalışma sonucumuzda, VAS değerlerinin boyun ağıısı olan hastalarda istatistiksel olarak anlamlı düzeyde yüksek bulunması, yukarıdaki literatür raporlarına dayandırılabilir.

Baş boyun ağrıları, kulak ağrısı, kulak çınlaması, baş dönmesi gibi bulgular sıklıkla diş hastalıkları ve temporomandibular eklem hastalıklarıyla birlikte görülebilen bulgular olabileceği gibi, zaman zaman nevraljik nedenlerle de aynı semptomların görülebileceği bildirilmiştir. ${ }^{25}$ Bu sebeple hastadaki semptomlar detaylı biçimde değerlendirilip gerekli tetkikler yapılmalı, ayırıcı tanılar göz önünde bulundurularak hastanın tedavi haritası buna göre çizilmelidir.

\section{SONUÇ}

Mevcut çalışma, migren, otolojik semptomlar, baş dönmesi ve boyun/omuz ağrısı ile TME ağrısı arasındaki ilişkinin değerlendirildiği bir çalışmadır ve bu yönüyle klinisyenlere ve prospektif çalı̧̧alara yön verebilecek bir pilot çalışma niteliği taşımaktadır. Özellikle migren ve boyun ağrısının, TME-VAS değeri ile ilişkili olabileceği bilgisini literatüre sunmaktadır. Bu bilgi, TME hastalarında migren ve boyun ağrılarının da sorgulanması ve birlikte değerlendirilmesi gerekliliğine işaret etmektedir. Çalışmamız, hasta sayısı limitasyonuna rağmen bu konudaki çalışmalara yön verebilecek nitelikte sonuçlar rapor etmektedir. İleride, daha geniş kapsamlı prospektif klinik çalışmalarla mevcut çalışma konusunu genişletilmesi planlanmaktadır.

NOT: Calışmada herhangi bir yazar, kurum ya da kuruluş ile çıkar çatışması içerisinde bulunmamaktadır. Makale daha önce hiçbir yerde yayınlanmamış ve yayınlanmak üzere işlem görmemektedir

\section{KAYNAKLAR}

1. Alomar X, Medrano J, Cabratosa J, Clavero JA, Lorente $M$, Serra $I$, et al. Anatomy of the temporomandibular joint. Semin Ultrasound CT MR 2007;28:170-83.

2. Mohl. Functional anatomy of the TM joint, in the President's Conference on the examination, diagnosis and management of TMJ. D.M. Laskin ve ark. (editors) ADA, Quintessence, Chicago, 1986.

3. Fernandes G, Franco AL, Siqueira JT, Goncalves $\mathrm{DA}$, Camparis CM. Sleep bruxism increases the risk for painful temporomandibular disorder, depression and non-specific physical symptoms. J Oral Rehabil 2012;39:538-44.

4. Mehta NM. The role of interprofessional education in the management of temporomandibular and sleep disorders. Cranio 2013;31:159-60.

5. Onder ME, Tuz HH, Kocyigit D, Kisnisci RS. Longterm results of arthrocentesis in degenerative temporomandibular disorders. Oral Surg, Oral Med, Oral Pathol, Oral Radiol Endod 2009;107:e1-5. 
6. Winocur E, Littner D, Adams I, Gavish A. Oral habits and their association with signs and symptoms of temporomandibular disorders in adolescents: a gender comparison. Oral Surg Oral Med, Oral Pathol, Oral Radiol Endod 2006; 102:482-7.

7. Dym $\mathrm{H}$, Israel $\mathrm{H}$. Diagnosis and treatment of temporomandibular disorders. Dent Clin North Am 2012; 56:149-61, ix.

8. Tuz HH, Onder EM, Kisnisci RS. Prevalence of otologic complaints in patients with temporomandibular disorder. American journal of orthodontics and dentofacial orthopedics : official publication of the American Association of Orthodontists, its constituent societies, and the American Board of Orthodontics 2003;123:620-3.

9. Racich MJ. Occlusion, temporomandibular disorders, and orofacial pain: An evidence-based overview and update with recommendations. J Prosthet Dent 2018;120:678-85.

10. Keersmaekers K, De Boever JA, Van Den Berghe L. Otalgia in patients with temporomandibular joint disorders. J Prosthet Dent 1996;75:72-6.

11. Morais AA, Gil D. Tinnitus in individuals without hearing loss and its relationship with temporomandibular dysfunction. Braz J Otorhinolaryngol 2012;78:59-65.

12. Hilgenberg PB, Saldanha AD, Cunha CO, Rubo JH, Conti PC. Temporomandibular disorders, otologic symptoms and depression levels in tinnitus patients. J Oral Rehabil 2012;39:239-44.

13. Graff-Radford SB. Temporomandibular disorders and headache. Dental clinics of North America. 2007; 51:129-44, vi-vii.

14. Israel HA, Davila $L$. The essential role of the otolaryngologist in the diagnosis and management of temporomandibular joint and chronic oral, head, and facial pain disorders. Otolaryngol Clin North Am 2014;47:301-31.

15. Wright EF, Syms CA 3rd, Bifano SL. Tinnitus, dizziness, and nonotologic otalgia improvement through temporomandibular disorder therapy. Mil Med. 2000;165:733-6.

16. Parker WS, Chole RA. Tinnitus, vertigo, and temporomandibular disorders. American J Dentofac Orthop 1995;107:153-8.

17. Florencio LL, de Oliveira AS, Carvalho GF, Dach F, Bigal ME, Fernandez-de-Las-Penas $C$, et al. Association Between Severity of Temporomandibular Disorders and the Frequency of Headache
Attacks in Women With Migraine: A CrossSectional Study. J Manipulative Physiol Ther 2017;40:250-4.

18. Fernandes G, Arruda MA, Bigal ME, Camparis CM, Goncalves DAG. Painful Temporomandibular Disorder is Associated with Migraine in Adolescents: a case-control study. J Pain 2019; 20; 1155-63.

19. Magalhaes BG, Freitas JLM, Barbosa A, Gueiros M, Gomes SGF, Rosenblatt $A$, et al. Temporomandibular disorder: otologic implications and its relationship to sleep bruxism. Braz J Otorhinolaryngol 2018;84:614-9.

20. Melchior MdeO MM, de Felício CM. Temporomandibu-lar disorders and parafunctional oral habits: an anamnesticstudy. Dental Press ] Orthod 2012;17:83-9.

21. Thalakoti S, Patil VV, Damodaram S, Vause CV, Langford LE, Freeman SE, et al. Neuron-glia signaling in trigeminal ganglion: implications for migraine pathology. Headache. 2007;47:1008-23; discussion 24-5.

22. Sessle BJ. Acute and chronic craniofacial pain: brainstem mechanisms of nociceptive transmission and neuroplasticity, and their clinical correlates. Crit Rev Oral Biol Med 2000;11:57-91.

23. de Felicio CM, Melchior Mde $O$, Ferreira $C L$, Da Silva MA. Otologic symptoms of temporomandibular disorder and effect of orofacial myofunctional therapy. Cranio. 2008;26:118-25.

24. De Laat A MH, Meuleman H, Stevens A, Verbeke G. Correlation between cervical spine and temporomandibular disorders. Clin Oral Investig 1998; 2: 54-7.

25. Tunçdemir AR BE, Çelebi H, Akın C. Bruksizmi olan hastalarda stiloid proces uzunluğunun belirlenmesi. Atatürk Üniv Diş Hek Fak Derg 2017;27:39-42. Hek Fak Derg 2017;27:39-42.

\section{Yazışma Adresi}

Zeynep GÜMRÜKÇÜ

Recep Tayyip Erdoğan Üniversitesi

Diş Hekimliği Fakültesi

Ağız Diş ve Çene Cerrahisi Anabilim Dalı

Rize, Turkiye.

Telefon No: +904642220000

Cep Tel. No.: 05302667222

E-mail: zeynep dt@hotmail.com zeynep.gumrukcu@erdogan.edu.tr 